\title{
Analysis of Cross-Border E-commerce Development in Jiangsu Province of China Based on SWOT
}

\author{
Shi Hong*, Shi Danqing, Huang Fei \\ School of Business, Hohai University, Nanjing, China \\ Email address: \\ shong6578@126.com (Shi Hong), shidanqing1102@163.com (Shi Danqing),745145304@qq.com (Huang Fei) \\ ${ }^{*}$ Corresponding author
}

\section{To cite this article:}

Shi Hong, Shi Danqing, Huang Fei. Analysis of Cross-Border E-commerce Development in Jiangsu Province of China Based on SWOT. Science Innovation. Vol. 4, No. 2, 2016, pp. 56-60. doi: 10.11648/j.si.20160402.16

Received: March 15, 2016; Accepted: March 31, 2016; Published: April 14, 2016

\begin{abstract}
The cross-border e-commerce presents an overall trend of continuously growing general scale, constantly enriching trading category and gradually expanding business market in China. On the basis, this paper will demonstrate the advantages, weaknesses, opportunities and challenges of cross-border e-commerce development in Jiangsu Province of China through SWOT analysis. Afterwards, the measures will be put forward from aspects including trade transition, platform construction, customs clearance efficiency, cross-border logistics and supervision system to promote cross-border e-commerce development of Jiangsu Province of China.
\end{abstract}

Keywords: Jiangsu Province, SWOT Analysis, Cross-Border E-commerce, Development

\section{基于SWOT分析的中国江苏省跨境电子商务发展探析}

\section{史虹*, 史丹青, 黄菲}

商学院, 河海大学, 南京, 中国

\section{邮箱}

shong6578@126. com(史虹)，shidanqing1102@163.com(史丹青), 745145304@qq.com(黄菲)

摘要：在总结中国跨境电子商务呈现总体规模持续增长、交易品类不断丰富、贸易市场逐渐扩大发展态势的基础上， 通过SWOT分析中国江苏省发展跨境电子商务的优势、劣势、机遇和挑战, 并从贸易转型、平台建设、通关效率、跨境 物流、监管体系等方面提出促进江苏跨境电子商务发展的措施。

关键词: 中国江苏省, SWOT分析, 跨境电子商务, 发展

\section{1. 引言}

跨境电子商务 (Cross-border E-commerce) 是指所 属不同国家或地区的交易主体，利用电子商务平台达成 交易、支付结算, 并通过跨境物流实现交易商品的运输 和配送的一种国际商业活动 [1]。跨境电子商务是电子商 务运行模式中较为高端的一种, 它突破了传统对外贸易
在全世界范围内时间、空间对贸易活动的限制，真正实 现了资金流、信息流、物流和商流的有机统一，为世界 各地的交易主体开拓了全球范围内的国际市场, 促进国 际贸易朝着高效率、低成本、宽领域的方向发展。如今, 跨境电子商务已渐渐成为中国政府推动经济发展、国内 企业进军国际市场的重要途径。但同时, 作为一个新的 经济形式, 跨境电子商务在发展的进程中仍然遇到很多 
的困难和挑战, 如何合理应对这些困难和挑战, 是中国 江苏省推动跨境电子商务健康持续发展的必要条件。

跨境电子商务的快速发展引起学术界的广泛关注。 郭卫萍等应用SWOT模型分析了中国跨境电子商务发展情 况, 从平台、物流、产品和政策四个方面提出中国跨境 电子商务的发展路径 [2]。孙伟等结合中国吉林省的实际 情况, 从物流、交易、信息、支付、决策等角度为吉林 省构建出跨境电子商务服务平台模型, 以促进中国吉林 省跨境电子商务的发展 [3]。程宇等分析了中国福建省发 展跨境电子商务的机遇和对策, 认为中国福建省应抓住 机遇, 通过培育电商服务产业链、建设第三方跨境支付、 建设信用体系、利用大数据精准营销等措施优化发展环 境 [4]。金丽静等阐述了发展跨境电子商务对于以生产小 商品为支柱产业的中国浙江省义乌市的重要性, 并提出 相关发展对策 [5]。

从现有的研究情况来看, 发展跨境电子商务的重要性 和迫切性已经得到了广泛的认可, 学者们从中国国家层面、 省级层面以及市级层面都做了相应的研究, 但对于中国江 苏省发展跨境电子商务的研究还有待进一步完善。

\section{2. 中国跨境电子商务发展总体态势}

\section{1. 总体规模持续增长}

近年来, 受全球经济危机影响, 中国对外贸易呈现疲 软态势, 而跨境电子商务表现出旺盛的成长势头, 进出口 交易额增长幅度超过 $30 \%$ 。相关数据显示，2014年中国跨 境电商交易规模 4.2 万亿, 同比增长 $33.3 \%$, 出口占比 $85.4 \%$; 各类跨境电子商务平台超过5000家, 通过这些平台开展跨 境商务活动的企业已超过20万家。2010-2015年中国跨境 电商交易规模如图1所示。

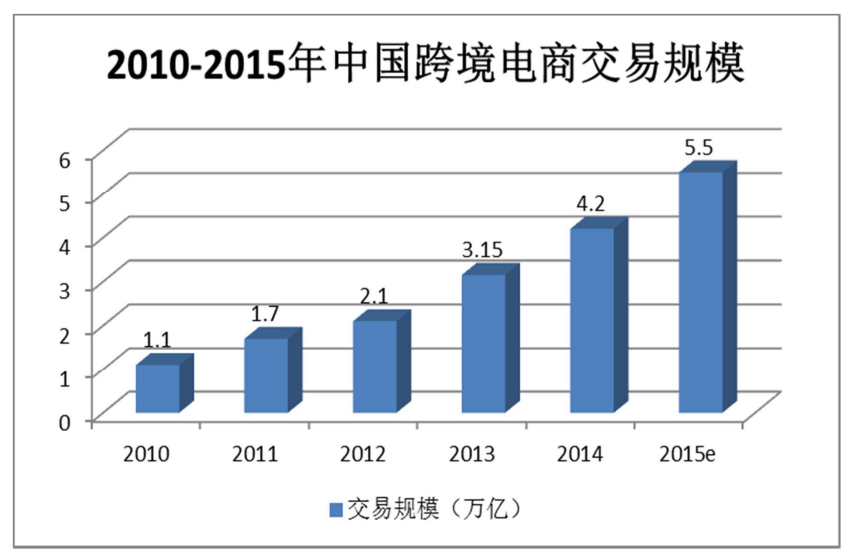

数据来源《2014年度中国电子商务市场数据监测报告》

图1 2010-2015年中国跨境电商交易规模。

另据阿里研究院与埃森哲联合发布的《全球跨境电商 趋势报告》预测, 2020年全球跨境电商仅零售交易规模或 将逼近 1 万亿美元, 惠及全球近 10 亿消费者, 而中国有望 成为全球最大的跨境零售交易市场, 带动全球跨境消费市 场年均提速近 $4 \%[6]$ 。

\section{2. 交易品类不断丰富}

据亚马逊中国发布的2015跨境电子商务趋势报告显 示, 相较于 2012 年, 2015年中国商家所售商品品类增加了 87倍 [7]。受国际市场青崃的中国商品也从以前的服饰、 电脑配件类不断向平板电脑、智能手机、扫地机器人、蓝 牙耳机、无人机等高科技、高质量产品扩充。

未来, 中国跨境电子商务的业务范围将进一步拓展。 据eBay大中华区统计，71\%的跨境大电商将在未来不断扩 充现有商品品类, 64\%的跨境电商大卖家打算延伸产品线, 这将持续提升中国跨境电子商务在全球跨境电商贸易中 的市场份额。

\section{3. 贸易市场逐渐扩大}

受经济发展水平、消费观念、物流状况等因素的影响, 以澳大利亚、西欧、北美为代表的成熟经济体一直是中国 跨境电子商务的主要市场, 并保持着良好的市场氛围和发 展势头; 同时, 随着金砖国家经济的崛起, 中国跨境电子 商务市场也在不断向这些新兴经济体快速扩展。此外, “一 带一路” 沿线国家也将成为中国跨境电子商务合作的重要 伙伴。

另据有关分析预测认为, 目前电子商务在东欧、中东 以及拉丁美洲、非洲等地区的覆盖率依然较低, 但有望受 经济全球化的新一轮影响和互联网技术的不断普及, 以上 地区在未来一段时间内将成为中国跨境电子商务市场扩 张的新方向。

\section{3. 江苏发展跨境电子商务的SWOT分析}

本节将在上一节对中国跨境电子商务总体态势分析 的背景下, 利用SWOT分析法剖析中国江苏省发展跨境电 子商务所具有的优势和劣势以及面临的机会和威胁, 明 确中国江苏省发展跨境电子商务的内外环境, 由此提出 相关发展对策。中国江苏省发展跨境电商SWOT分析模型 如表1所示。

表1 中国江苏省发展跨境电商SWOT分析模型。

\begin{tabular}{ll}
\hline 优势 (Strengths) & 劣势 (Weaknesses) \\
\hline & (1)核心企业实力欠缺, 行业整体 \\
(1)电子商务及配套产业基础好 & 能力不足 \\
(2)生产制造业发达 & (跨境物流发展滞后, 制约跨境 \\
(3)进出口优势明显, 经济外向度高 & 电商发展 \\
(4)相关专业人才储备丰富 & (3)商品出关不便, 通关效率低 \\
& (4)相关法律体系不健全、监管体 \\
& 系不完善 \\
机遇 (Opportunities) & 挑战 (Threats) \\
\hline 1)中国国家政策的大力支持 & (1)中国上海自贸区虹吸效应的 \\
(2)系列中国国家战略的提出 & 挑战 \\
产业转型升级的迫切需要 & (2)中国其他试点省市的挑战 \\
\hline
\end{tabular}

\section{1. 优势分析}

（1）电子商务及配套产业基础好。中国江苏省经济 发达, 互联网普及率高, 并且在互联网基础设施建设、网 络构建、经营管理模式创新以及软件的开发与应用等方面 都有很大的优势, 为开展跨境电子商务打下坚实的基础。 首先, 中国江苏省互联网普及情况优于全国水平。相关数 
据显示，2015年中国江苏省互联网网民人数已达到 4274 万人，位居中国第二，较上一年度增长 $4.4 \%$, 互联网普及 率达到了 $53.8 \%$ ，位居中国第八。其次，宽带服务能力不 断提升。2015年中国江苏省家庭固定宽带平均接入速度为 $10.5 \mathrm{Mbps}$ ，较 2014 年提升 $12.5 \%$; 移动宽带平均接入速率 为 18. 59Mbps, 光纤线路总长度达到 205.4 万公里, 位列中 国第一。再者，电商交易平台众多。目前中国江苏省有超 过36万家网站，其中有 4 家企业入围2015年中国互联网企 业100强，涌现出一批中国知名的电商交易平台，如苏宁 易购、焦点科技等。同时，农村电商发展迅猛，如中国江 苏省沭阳县因家家开网店而被誉为 “中国淘宝第一县”。

（2）生产制造业发达。改革开放以来，在以 “苏南 模式” 为动力, 以 “苏北速度” 为推力下, 中国江苏省生 产制造业发展水平得到了快速提升, 呈现出产业基础好、 生产能力强、市场活力足等总体特征, 这为中国江苏省发 展跨境电子商务奠定了扎实的物质基础。2014年, 中国江 苏省规模以上制造业企业单位 48082家，创造工业总产值 超过 13.7 万亿元, 其中销售产值 13.6 万亿, 出口交货值 2.3 万亿, 位居中国前列。近年来, 随着科技水平不断提升, 中国江苏省在服装、棉纺、家电、零部件加工等传统制造 领域继续保持一定优势的同时, 在新能源汽车、计算机、 碳纤维、航空航天装备等新兴制造领域表现出良好的成长 势头, 这将进一步巩固江苏省作为中国制造大省的地位。

(3) 进出口优势明显, 经济外向度高。经济外向度 是指一定时期内一国或一地区的进出口贸易值与该国或 该地区同时期内的国民生产总值的比值, 经济外向度越高 表明国际市场对该地区产品的认可程度越高, 就越有利于 开展跨境电子商务 [8]。江苏省作为中国东部沿海省区, 改革开放的前沿, 对外贸易一直保持良好的发展态势。 2008-2014年江苏省与中国全国经济外向度比较如表2。

表2 江苏省与中国全国经济外向度比较。

\begin{tabular}{lllll}
\hline \multirow{2}{*}{ 年份 } & $\begin{array}{l}\text { 江苏贸易总 } \\
\text { 额 (亿美元) }\end{array}$ & $\begin{array}{l}\text { 江苏经济 } \\
\text { 外向度 }(\%)\end{array}$ & $\begin{array}{l}\text { 全国贸易总 } \\
\text { 额 (亿美元) }\end{array}$ & $\begin{array}{l}\text { 全国经济 } \\
\text { 外向度 (\%) }\end{array}$ \\
\hline 2008 & 3922.68 & 92 & 25616.3 & 62 \\
2009 & 3388.32 & 67 & 22072.2 & 44 \\
2010 & 4657.93 & 77 & 29727.6 & 51 \\
2011 & 5397.59 & 73 & 36421.0 & 51 \\
2012 & 5480.93 & 64 & 38667.6 & 47 \\
2013 & 5508.44 & 58 & 41597.0 & 46 \\
2014 & 5637.62 & 53 & 43030.0 & 42 \\
\hline
\end{tabular}

表格数据来源于对中国国家统计局相关数据的整理和计算

（4）相关专业人才储备丰富。江苏省作为中国教育 大省, 在与开展跨境电子商务相关的电子商务、国际贸易、 金融会计、物流工程、法律、计算机技术等诸多领域都有 较高的科研水平; 中国江苏省高校众多, 开设的相关专业 吸引大量的有志青年。同时, 中国江苏各级政府注重产学 研一体化的发展理念, 在其引导下诸多高校与企业建立了 产学研一体化合作项目, 先后成立了电子商务行业研究院、 电子商务认证中心、中国江苏省电子商务重点实验室等专 门性的促进电子商务研究与发展的科研机构, 为中国江苏 省开展跨境电子商务培养了大量的素质高、专业技能强的 复合型人才。
此外，中国江苏省的区位条件、交通基础设施等因素 对于发展跨境电子商务都是极大的优势。

\section{2. 劣势分析}

虽然中国江苏省发展跨境电子商务存在诸多明显的 优势, 但同样存在一些相对劣势, 限制了中国江苏省跨境 电子商务的发展。

（1）核心企业实力欠缺，行业整体能力不足。虽然 近些年伴随着互联网技术的日新月异, 中国江苏省电子商 务得到较大的发展, 涌现出一批比较知名的互联网电商企 业, 但与中国其他省市相比, 其数量与市场竞争力都存在 比较大的差距。以2014年网络零售领域市场份额而言, 天 猫（中国浙江）占59.3\%份额，稳居第一; 京东（中国北 京）占据 $20.2 \%$ 份额, 位列第二; 苏宁易购（中国江苏） 第三, 占比3. 1 \% 。虽然苏宁易购位居第三, 但是其市场份 额与天猫、京东相比, 相距甚远。此外, 从中国江苏省整 体来看, 行业内电商企业以中小型为主, 其经营管理方式、 发展战略、生存环境等都存在明显的不足, 难以借势成长 为具有影响力的综合性电商企业, 致使中国江苏省电商行 业缺乏足够的市场势力。

（2）跨境物流发展相对滞后，制约跨境电商发展。 跨境电子商务的发展离不开跨境物流作为有力的支撑, 中 国江苏省在涉及到对外贸易领域的物流支撑体系仍不够 完善, 发展相对滞后, 主要表现在: 第一, 缺乏本土化国 际物流企业, 过度依赖于第三方。跨境物流需要有成熟的 跨国物流企业在海外建设一定的物流基础设施, 形成更加 完善的国际物流体系, 而中国江苏省正是缺少这样的成熟 国际物流企业, 且缺乏与国际上知名物流企业合作。同时, 众多中小电商企业为了达成交易, 只能通过成本高、速度 慢的传统邮政或国际快递实现商品的递送, 极大削弱了跨 境电商的便捷性。第二, 跨境物流的信息化水平依然较低, 整合行业物流信息和资源的能力尚显不足, 依然存在大量 物流“信息孤岛”现象，限制了跨境电商健康、持续发展。

(3) 商品出关不便, 通关效率低。货物出关要先申 请报关, 其一系列繁琐的手续不仅耗费大量的时间, 也产 生了一定的费用, 长此以往给消费者和商家带来沉重的经 济负担。同时，货物因各种原因导致申报失败而滞留在海 关的情况也是经常出现, 这不仅耽误消费者签收商品, 更 是损害了跨境电子商务卖家的信誉。中国江苏省虽然在苏 州市试行电子通关放行, 但仅仅是少数重点进出口企业获 准，而中国江苏省绝大多数中小跨境电商企业因为资金不 足、信息化技术薄弱，并不能与政府电子政务平台实现很 好的数据对接与共享, 极大地制约电子通关在中国江苏全 省范围内的普及与应用, 通关效率依然没有得到提升。

（4）相关法律体系不健全、监管体系不完善。近年 来, 随着跨境电子商务的快速发展, 而与之相配套发展的 法律体系、监管体系在江苏省以及中国全国范围内都尚未 建立和完善。跨境电子商务是在虚拟的互联网平台上面向 全球消费者进行的交易，在交易的过程中存在诸多不确定 因素, 由于缺乏相关法律的制约, 一些不法商家出售假冒 伪劣产品，不仅有损 “中国制造” 的国际形象，更是扰乱 跨境电子商务的市场秩序。与中国国内市场相比, 跨境电 
子商务处在更加复杂、多变的国际市场环境，而中国江苏 省尚未就涉及跨境电子商务支付、税收、信用等诸多方面 建立健全监管体制, 跨境电子商务发展受到制约。

\section{3. 机遇分析}

（1）中国国家政策的大力支持。2015年5月，中国国 务院先后出台《关于大力发展电子商务加快培育经济新动 力的意见》和《关于加快培育外贸竞争新优势的若干意见》, 提出提升跨境电子商务通关效率, 培育一批具有代表性的 跨境电子商务平台和企业, 并将跨境电子商务作为新型贸 易发展方式。2015年6月, 中国政府又出台《关于促进跨 境电子商务健康快速发展的指导意见》, 对大力发展跨境 电子商务做出了重要部署。2016新年伊始, 中国国务院即 印发《关于同意在天津等 12 个城市设立跨境电子商务综合 试验区的批复》，同意包括中国江苏省苏州市在内的 12 个城市设立跨境电子商务综合试验区。如此密集地出台促 进电子商务发展的政策, 表明中国政府对此高度重视和大 力支持, 江苏省应该抓住机遇, 充分利用政策红利, 推动 跨境电子商务发展。

(2) 系列中国国家战略的提出。在全球经济低迷, 国内经济发展放缓的情况下, 中国提出了一系列的发展战 略, 为跨境电子商务的发展提供良好的机遇。2015年中国 “两会” 提出 “互联网+” 战略后, 在全社会掀起了 “大 众创业、万众创新” 浪潮, 越来越多的传统贸易企业借助 互联网实现小批量、多批次的网上经营, “互联网+贸易” 形式成为传统贸易发展的新趋势。“一带一路” 是新形势 下中国提出又一大国际战略, 中国江苏省作为“一带一路” 的重要节点, 对于江苏省与沿线国和地区开展跨境电子商 务有着极其重要的意义, 将极大地促进江苏省跨境电子商 务的发展。此外，2015年12月20日，中韩、中澳自贸协定 同日生效，关税逐年递减，给中国江苏省对该地区的电子 商务发展创造了良好的市场环境。

（3）产业转型升级的迫切需要。中国江苏省市虽然 是生产制造大省, 但总体创新能力和技术水平有待进一步 提高。传统的高能耗、低技术的粗放式生产已经不能适应 可持续发展需求, 新形势下推动江苏省产业升级发展、转 变经济发展形式已是迫在眉睫, 而发展跨境电子商务的作 用不言而喻。

\section{4. 挑战分析}

(1) 中国上海自贸区虹吸效应的挑战。中国上海自 贸区在跨境电子商务领域先试先行, 大力改革创新, “跨 境通” 平台已经运行, 并收到很好的效果。该平台依托中 国上海自贸跨境电商物流中心和已经优化创新的报关报 检、跨境外汇支付系统, 简化出关手续, 缩短报关时间, 为企业大大地节约了贸易成本, 提高了通关效率。也正是 因此, 利好政策吸引着中国江苏省跨境电商企业向中国上 海自贸区内转移, 给江苏省发展跨境电子商务带来极大的 挑战。

（2）中国其他试点省市的挑战。平台市场具有明显 的 “路径依赖性”, 较早开展跨境电子商务的企业利用不 断积累的客户群体和良好的市场口碑, 能够有效扩大网络
效应形成微边际成本扩张效应, 这无疑是缩小了中国江苏 省开拓跨境电子商务国际市场的空间。目前, 中国上海市、 中国杭州市、中国宁波市、中国郑州市等跨境电子商务试 点城市在 “先试先行” 思想的指导下, 已逐渐探索出一些 促进区域跨境电子商务的发展方式, 这同样给中国江苏省 带来不小的挑战。

\section{4. 基于SWOT分析的中国江苏发展跨境电子商务 的对策}

通过SW0T分析充分了解到中国江苏省发展跨境电子 商务的优势与不足, 以及面临的主要问题, 在此基础上提 出江苏省跨境电子商务的发展总体思路：政府主导、企业 驱动, 多方参与, 以市场为导向, 以降低跨境电商交易成 本, 提高交易效率, 促进中国江苏省贸易转型升级为目的, 坚持平台化、品牌化、信息化和规范化的发展方向, 破除 发展藩篱, 营造良好的跨境电商发展环境。

（1）鼓励传统外贸企业转型发展。跨境电商作为中 国外贸调结构、稳增长的重要方式, 江苏省应该抓住中 国大力发展跨境电子商务的机遇, 鼓励传统贸易企业向 线上转移。传统外贸企业正面临着订单零散减少、配套 服务滞后的窘境。对此, 中国江苏省要引导传统外贸企 业大胆拥抱互联网思维, 整合传统外贸企业服务体系, 大力发展跨境电子商务。同时, 中国江苏省要发挥自身 制造产业优势, 推动生产制造企业与跨境电商企业合作, 拓宽贸易渠道, 扩大国际销售市场, 推动中国江苏省传 统外贸转型发展。

（2）打造品牌化跨境电商。电商平台是发展跨境电 商贸易的重要工具, 中国江苏省要利用好自身存在的优 势, 构建具有江苏省特色的跨境电商平台, 同时鼓励中 小电商企业不断提升产品质量和服务水平, 创建自主品 牌, 打造出一批在中国国内、国际上知名电商企业, 进 一步提升中国江苏省跨境电商行业整体水平。政府部门 要加大政策支持力度, 扶持重点发展企业在跨境电子商 务领域抢先占领一席之地, 打造中国江苏省品牌效应; 统筹配置中国江苏全省发展资源, 着力改善江苏中部、 北部地区跨境电商发展环境和发展水平。同时, 企业方 面要诚信经营, 拒绝假冒伪劣产品, 改变 “中国制造” 产品低品质、低价格的形象。

（3）构建高效跨境物流体系。现代物流业作为中国 江苏省重点发展领域, 但从目前的发展现状来看, 距离 发展目标仍有较大的提升空间。构建高效的跨境物流体 系要求中国江苏省从宏观角度规划发展蓝图, 如规划构 建物流园区、物流中心和配送站点三级物流体系; 从微 观角度加大物流基础设施的建设, 特别是鼓励江苏省本 土企业在国际主要出口市场布局海外仓, 不断完善跨境 物流体系覆盖范围。构建高效的跨境物流体系还要求中 国江苏省整合交通、邮政、港口、企业等现有物流资源, 建立覆盖江苏全省的开放式物流信息化平台, 并实现与 中国其他省份平台对接合作, 为企业提供物流供需信息、 货物跟踪、人才智库等服务 $[9]$ 。此外, 中国江苏省也要 
鼓励本土物流企业加强与国际物流企业合作, 积极探索 发展跨境物流新模式。

（4）提高跨境电商通关效率。苏州市作为中国江苏 省唯一首批跨境电子商务综合试点城市, 江苏省要以此 为契机, 改革创新海关监管体系, 提高通关效率。为此 中国江苏省首先要加快完善现有公共服务平台, 破除信 息壁垒，整合海关、国检、外管、电商企业、物流企业 以及第三方服务平台系统数据, 推动各部门之间的信息 共享, 真正实现 “一站式” 通关 [10]。其次, 针对小额 跨境电商构建综合性入驻平台, 如中国上海自贸区 “跨 境通” 平台, 通过该平台实现集中通关，从而减少通关 手续和成本, 提高通关效率。此外, 江苏省要积极关注 中国四大自贸区以及其他省市在跨境电子商务领域制度 建设, 对于成熟有效的经验, 江苏省要有针对性加以复 制、实施。

（5）建立健全跨境电商监管体系。国际市场作为电 子商务跨境交易的重要市场, 相关法律、监管制度的建 设一直受到格外瞩目。中国江苏省要结合国际市场环境 建立健全跨境电子商务的法律体系, 使解决跨境贸易争 端有法可依, 保护买卖双方的合法权益。同时要研究制 定符合跨境电子商务企业发展的市场监管制度和产品质 量追溯机制, 依法加强对中国江苏全省跨境电商平台和 相关企业的监管，严厉打击销售假冒伪劣商品的违法行 为, 维护江苏省跨境电子商务在国际市场中的品牌形象。 针对国际间的贸易争端, 要加强双边、多边跨境电子商 务政府合作、行业协会合作和企业合作，建立纠纷解决 机制 [11]。

\section{5. 结束语}

跨境电子商务已经成为中国对外贸易转型发展的必 然趋势, 中国江苏作为制造业大省只有抓住机遇, 相关部 门精诚团结, 结合自身优势, 破除发展藩篱, 积极应对挑 战, 推动传统贸易向跨境电子商务转型、建设具有江苏省 特色的品牌化电商平台、构建高效跨境物流体系、提高通 关效率、不断完善相关法律法规，才能促进中国江苏省跨 境电子商务健康持续发展。

\section{致谢}

本文为江苏企业国际化决策咨询研究基地、中央高校 基本科研业务费项目《江苏加强与中国上海自由贸易试验 区对接合作研究》（项目编号2014B20814）的阶段性成果 之一。

\section{参考文献}

[1] 李昱蓉. 中国跨境电子商务的现状及建议 $[J]$. 中国管理信 息化, 2015, (04)：174-175.

[2] 郭卫萍, 王丽霞. 基于SWOT分析的我国跨境电商发展路径研 究 [J]. 价值工程, 2015, (32) : 54-56.

[3] 孙伟, 赵文珺. 吉林省跨境电子商务服务平台构建 $[J]$. 情报 科学, $2015,(06)$ : 106-108+119.

[4] 程宇, 陈明森. 福建跨境电子商务发展机遇与对策 [J]. 亚太 经济, 2014, (05) : 115-120.

[5] 金丽静. 基于SWOT分析义乌中小企业发展跨境电商的现状 及对策 $[J]$. 现代商业, 2015，(11)：110-111.

[6] 阿里研究院. 阿里跨境电商研究中心与埃森哲发布2020全 球跨境电商趋势报告. 2015 年 6 月 14 日. -http://www. aliresearch. com/blog/article/detail /id/20477. html

[7] 亚马逊中国发2015跨境电子商务趋势报告. 2015年12月 11 日. -http://roll. sohu. com/20151211/n430923895. shtm1

[8] 北京市统计局外向型经济外经统计课题研究组. 关于建立 外向型经济统计指标体系的研究 [J]. 统计研究, 1992, (04) : 26-31.

[9] 吴勇, 冯耕中, 王能民. 我国典型物流公共信息平台商业模 式的比较研究 [J]. 商业经济与管理, 2013, (10): 14-21.

[10］孙蕾, 王芳. 中国跨境电子商务发展现状及对策 $[J]$. 中国流 通经济, 2015, (03): 38-41.

[11] 来有为, 王开前. 中国跨境电子商务发展形态、障碍性因素 及其下一步 $[J]$.改革, 2014，(05)：68-74. 